\title{
Assessment Of Class II Caries MOD Visited In Hospital: A Three Months Retrospective Analysis.
}

\author{
Ankita Agrawal ${ }^{1}$, Rashmi Sinha², Suraj Kumar ${ }^{3}$, Kumar Abhinav ${ }^{4}$ \\ ${ }^{1} \mathrm{MDS}$ (Conservative and Endodontics), Senior Resident, Nalanda Medical College \& Hospital, Patna, Bihar, India, ${ }^{2}$ MDS (Orthodontics and Dentofacial \\ Orthopaedics), Senior Resident, Nalanda Medical College \& Hospital, Patna, Bihar, India, ${ }^{3}$ MDS (Oral and Maxillofacial Surgeon), Senior Resident, Nalanda Medical \\ College \& Hospital, Patna, Bihar, India, ${ }^{4}$ Senior Resident, DNB Neurosurgery, Lilavati Hospital and Research Centre, Mumbai, Maharashtra, India.
}

\section{Abstract}

Background: Dental caries is a multifactorial oral disease which affects humans of any age, sex, race and socioeconomic status. The present study was retrospectively conducted to assess the prevalence of class II MOD caries patients visited in a department over the period of 3 months. Subjects and Methods: The present study was conducted retrospectively in which record of 250 patients were examined to check the prevalence of Class II MOD cavities. Patients were selected from the out-patient department of Conservative Dentistry. Before commencement of the study permission was taken from ethical committee of the institution.In this study we recorded only class II MOD caries. Results: In our study we examined 250 patients for Class II MOD caries. In 250 patients 76 (30.4\%) patients had Class II MOD caries. The class II MOD caries was prevalent in age group 31-40 years (36.84\%). Conclusion: Our study concluded that class II MOD was more prevalent than any other carious lesion. The class II MOD caries was prevalent in age group 31-40 years.

Keywords: Class II MOD, Dental Caries.

Corresponding Author: Dr. Rashmi Sinha, MDS (Orthodontics and Dentofacial Orthopaedics), Senior Resident, Nalanda Medical College \& Hospital, Patna, Bihar, India.

Received: September 2019

Accepted: September 2019

\section{Introduction}

Dental caries is the most prevalent chronic disease affecting humans irrespective of age, sex, race and socioeconomic status. ${ }^{[1]}$ As around $90 \%$ of school children and most of the adults have been affected by dental caries, hence it has been considered as the most important global oral health burden. ${ }^{[2]}$ Dental caries is a major oral health problem affecting 2.43 billion people (35.3\% of the population) worldwide in the year 2010. ${ }^{[3]}$ Dental caries is a multifactorial disease; several factors play a role in the initiation and progression of the lesion including environmental factors, host, and behavioral factors. ${ }^{[4]}$ Dental caries causes pain as well as local and systematic infection. It will progress into tooth pulp and a dental abscess will form if untreated. Moreover, it affects children's nutrition, growth and development, general health and quality of life. ${ }^{[5]}$ According to the World Health Organization (WHO 1997), detection of dental caries in surveys has been performed at cavitation level because examiners frequently cannot reliably assess the non-cavitated lesions. However, the inclusion of non-cavitated caries lesions is necessary since these can be arrested through certain preventive measures and lowering the cost of restorative treatment. ${ }^{[6]}$ The present study was retrospectively conducted to assess the prevalence of class II MOD caries patients visited in a department over the period of 3 months.

\section{Subjects and Methods}

The present study was conducted retrospectively in which record of 250 patients were examined to check the prevalence of Class II MOD cavities. Patients were selected from the out-patient Department of Dentistry, Nalanda Medical College \& Hospital, Patna, Bihar, India..Before commencement of the study permission was taken from ethical committee of the institution. A diagnostic criteria for clinical examination was followed wherein, caries was detected according to WHO criteria that "clinically the caries was recorded as present when a lesion in a pit or fissure or on a smooth surface had a detectable softened floor, undermined enamel or softened wall. On Proximal surface it had to be certain that the explorer had entered the lesion or taking bitewing radiograph for any doubt existed caries"7. Black in 1908 classified carious lesion by location as follow:

- Class I: These are including occlusal surface, buccal and lingual pits of posterior teeth and lingual surface of anterior teeth.

- Class II: These are involving proximal surface of posterior teeth.

- Class III: These are involving proximal surface of anterior teeth that do not include the incisal edge.

- Class IV: These are involving the proximal surface of 
anterior teeth that include the incisal edge

- Class V: These are involving the gingival third of the facial or lingual surface of all teeth. ${ }^{[8]}$

Carious lesions that were found on the incisal edge or cusp tips were excluded from the present study as it's not recommended by GV Black. In this study we recorded only class II MOD caries.

\section{Results}

In our study we examined 250 patients for Class II MOD caries. In 250 patients $76(30.4 \%)$ patients had Class II MOD caries. The class II MOD caries was prevalent in age group 31-40 years (36.84\%).

\section{Table 1: Prevalence of class II MOD.}

\begin{tabular}{|l|l|}
\hline GV Black classification & No. $(\%)$ \\
\hline Class 1 & $42(16.8 \%)$ \\
\hline Class 2(MO) & $59(23.6 \%)$ \\
\hline Class 2(DO) & $40(16 \%)$ \\
\hline Class 2 (MOD) & $76(30.4 \%)$ \\
\hline Class 3 & $15(6 \%)$ \\
\hline Class 4 & $11(4.4 \%)$ \\
\hline Class 5 & $7(2.8 \%)$ \\
\hline
\end{tabular}

Table 2: Prevalence of class II MOD according to age group.

\begin{tabular}{|l|l|}
\hline Age group & No. $(\%)$ \\
\hline $20-30$ & $21(27.63 \%)$ \\
\hline $31-40$ & $28(36.84 \%)$ \\
\hline $41-50$ & $12(15.78 \%)$ \\
\hline $51-60$ & $6(7.8 \%)$ \\
\hline $61-70$ & $9(11.84 \%)$ \\
\hline
\end{tabular}

\section{Discussion}

The increase in caries prevalence is mostly due to lack of oral health care system, because this systems mostly focus on curative care, but there is no periodical implementation of community health prevention and oral health promotion. ${ }^{[9]}$ The World Health Organization (WHO) has ranked it as number three among all chronic noncommunicable diseases that require worldwide attention for prevention and treatment. ${ }^{[10]}$

In our study we examined 250 patients for Class II MOD caries. In 250 patients $76(30.4 \%)$ patients had Class II MOD caries. The class II MOD caries was prevalent in age group 31-40 years (36.84\%).

A study done by Azam et al, which stated that recent clinical and experimental caries research confirm the impact of hormonal fluctuations and pregnancy on the quantity and quality of saliva, and thereby on oral ecology, so the physiological mechanisms by which life-history events have a more direct and significant influence on poorer dental health in women than in men is becoming clearer. ${ }^{[11]}$

Ismail et al., found gender to be a dental caries predictor, with boys being more affected than girls, and this variation could be attributed to the different age group and geographic locations of that study. ${ }^{[12]}$
The studies done by Goyal et al., and Dash et al., where the increase in prevalence occurred till nine years of age, after which there was a decrease in the caries prevalence until the age of 12 and 15 years. ${ }^{[13,14]}$

RM $\mathrm{T}$ et al conducted a study according to GV Black classification of dental caries in which (7885) carious lesions were detected on various surfaces, class I buccal surface $387(4.9 \%)$, class I palatal surface $465(5.8 \%)$, class I occlusal surface $4836(61.3 \%)$, class II mesioocclusal (MO) 499 (6.3\%), class II disto-occlusal (DO) 594 (7.5\%), class II mesio-occlusal-distal (MOD) $215(2.7 \%)$, class III mesial 331 (4.1\%), class III distal 289 (3.6\%), class IV $95(1.2 \%)$, class V 174 were $(2.2 \%)$. ${ }^{[15]}$

\section{Conclusion}

Our study concluded that class II MOD was more prevalent than any other carious lesion. The class II MOD caries was prevalent in age group 31-40 years.

\section{References}

1. Peterson PE. The World Oral Health Report 2003: Continuous improvement of oral health in the $21^{\text {st }}$ century - the approach of the WHO Global Oral Health programme. Community Dentistry and Oral Epidemiology. 2003;31(Supp-1):3-24.

2. Peterson PE. The global burden of oral diseases and risk to oral health. Bulletin of the World Health Organization. 2005;83(9):66169.

3. Vos T, Flaxman AD, Naghavi M, Lozano R, Michaud C, Ezzati M, et al. Years lived with disability (YLDs) for 1160 sequelae of 289 diseases and injuries 1990-2010: a systematic analysis for the Global Burden of Disease Study 2010. Lancet. 2012;380(9859):2163-2196. doi: 10.1016/S0140-6736(12)61729-2.

4. Shaffer JR, Feingold E, Wang X, Lee M, TCuenco K, Weeks DE, et al GWAS of dental caries patterns in the permanent dentition. J Dent. Res 2013:;92(38).

5. Li M, Zhou Y, Qiu RM, Lin HC. Impact of early childhood caries on oral health-related quality of life of preschool children. Eur J Paediatr Dent. 2015;16:65-72.

6. Pitts N. 'ICDAS' - an international system for caries detection and assessment being developed to facilitate caries epidemiology, research and appropriate clinical management. Community Dent Health. 2004;21(3):193-98.

7. HegdaMN,Hegda P, Bhat R. Prevalence of dental caries in anterior teeth in South Canara population- a three year epidemiological study.IJAR 2014;4(2).

8. Nomann NA, Polan MAA, Jan CM, Rashid F and Taleb A. Amalgam and composite restoration of posterior teeth. Bangladesh J Dent Res Educ 2013;3(1).

9. Sudha P, Bhasin S, Anegundi RT. Prevalence of dental caries among 5-13 year old children of Mangalore city. J Indian SocPedodPrev Dent. 2005;23(2):74-79.

10. Marrs JA, Trumbley S, Malik G. Early childhood Caries determining the risk factors and assessing the prevention stratergies for nursing intervention. PediatrNurs. 2011;37(1):9-15.

11. Azam S, Khurram MS, Hassan M, Iqbal F, Iqbal S. Distribution of dental caries and its relationship to risk factor Pak Oral Dental J 2011:31(2)

12. Ismail AI, Sohn W, Tellez M, Willem JM, Betz J, Lepkowski J. Risk indicators for dental caries using the International Caries Detection and Assessment System (ICDAS) Community Dent Oral Epidemiol. 2008;36(1):55-68. 


\section{Agraual et al; Assessment Of Class $I J I$ Caries MOD Visited In Haspital: A I Free Manths Retraspective}

\section{Analysis.}

13. Goyal A, Gauba K, Chawla HS, Kaur M, Kapur A. Epidemiology of dental caries in Chandigarh school children and trends over the last 25 years. J Indian SocPedo Prevent Dent. 2007;25(3):115-18.

14. Dash JK, Sahoo PK, Bhuyan SK, Sahoo SK. Prevalence of dental caries and treatment needs among children of Cuttack (Orissa) J
Indian SocPedoPrev Dent. 2002;20(4):139-43.

15. RM T, RO I. Prevalence And Distribution Of Dental Caries Experience According To GV Black Classification For Patient Attending To Dental School. Journal of Oral Health \& Community Dentistry. 2015 Apr 1;9(2).

Copyright: (C) the author(s), 2019. It is an open-access article distributed under the terms of the Creative Commons Attribution License (CC BY 4.0), which permits authors to retain ownership of the copyright for their content, and allow anyone to download, reuse, reprint, modify, distribute and/or copy the content as long as the original authors and source are cited.

How to cite this article: Agrawal A, Sinha R, Kumar S, Abhinav K. Assessment Of Class II Caries MOD Visited In Hospital: A Three Months Retrospective Analysis. Asian J. Med. Res. 2019;8(3):DE01-DE03.

DOI: dx.doi.org/10.21276/ajmr.2019.8.3.DE1

Source of Support: Nil, Conflict of Interest: None declared. 